\title{
Changes in health utilities and health-related quality of life over 12 months following radical prostatectomy
}

\author{
Jennifer Ku, BHSc, MSc (Cand); Murray Krahn, MD, MSc, FRCPC; John Trachtenberg, MD, FRCSC, FACS; \\ Michael Nesbitt, BA; Robin Kalnin, BMus; Gina Lockwood, MMath; Shabbir M.H. Alibhai MD, MSc, FRCPC
}

See related article on page 453

\section{Abstract}

Introduction: Although radical prostatectomy (RP) is an effective treatment for prostate cancer, it has potentially deleterious effects on health-related quality of life (HRQoL). Utility is an important global measure of HRQoL. This utility is also used in decisionmaking models and economic evaluations. There are no published prospective data characterizing men's utilities for health outcomes post-RP.

Methods: From July 2003 to June 2006, patients undergoing RP at the University Health Network in Toronto, Ontario, Canada, completed the Patient-Oriented Prostate Utility Scale (PORPUS), a disease-specific HRQoL and utility instrument. Men were included if they had clinically localized prostate cancer and had completed HRQoL measures prior to surgery and at least once within 9 to 18 months after the RP. Health-related quality of life was measured prior to surgery and at 4 stages after surgery: 0 to 3 months, 3 to 9 months, 9 to 18 months, and 18 to 30 months. Statistical analyses included pairwise t-tests and multivariable linear regression comparing changes in scores between baseline and the 9- to 18-month range.

Results: Two hundred and thirteen men (mean age 60.9, median Gleason score 7) met the inclusion criteria. At baseline, HRQoL was high (mean PORPUS-P [psychometric] $=83.8$ ). Scores declined sharply by 3 months $(65.5, p<0.001)$ and improved but did not reach baseline by $9-18$ months $(75.1, p<0.001)$. Utility scores (PORPUS-U[utility]) showed the same pattern: 0.94 at baseline; 0.81 at 3 months $(p<0.001)$; and 0.88 at 9 to 18 months ( $p<$ 0.001). Predictors of HRQoL, including baseline PORPUS score, nerve-sparing surgery and smoking status, decline after RP.

Conclusion: Symptom scores are known to be affected up to 12 months after RP. Our study demonstrates that global health status also declines and remains affected 1 year after surgery.

Can Urol Assoc J 2009;3(6):445-52

\section{Résumé}

Introduction : La prostatectomie radicale est un traitement efficace contre le cancer de la prostate, mais elle présente des effets indésirables potentiels ayant un impact sur la qualité de vie liée à la santé (QdVS), dont l'état de santé est une importante mesure globale. Cette mesure est aussi utilisée dans les modèles décisionnels et les évaluations économiques. Aucune donnée prospective n'a été publiée concernant l'état de santé des patients après une PR.

Méthodologie : Entre juillet 2003 et juin 2006, des patients ayant subi une PR au sein du University Health Network à Toronto (Ontario) au Canada ont rempli le questionnaire PORPUS d'auto-évaluation, un instrument de mesure de la qualité de vie reliée à la santé et de l'état de santé. Étaient inclus les hommes atteints d'un cancer de la prostate cliniquement localisé et ayant été évalués à l'aide d'instruments de mesure de la QdVS avant l'intervention chirurgicale et au moins une fois dans les 9 à 18 mois suivant la PR. La qualité de vie reliée à la santé a été mesurée avant la chirurgie et à 4 reprises par la suite : après 0 à 3 mois, 3 à 9 mois, 9 à 18 mois et 18 à 30 mois. Les analyses statistiques incluaient des tests t par paires et une analyse de régression linéaire multivariée afin de comparer les changements dans les scores entre les valeurs de départ et les valeurs obtenues 9 à 18 mois après l'intervention.

Résultats : Deux cent treize hommes (âge moyen, 60,9 ans, score de Gleason médian, 7) répondaient aux critères d'inclusion. Au départ, les scores de QdVS étaient élevés (score PORPUS-P [psychométrique] moyen $=83,8)$. Les scores avaient chuté dramatiquement après 3 mois $(65,5, p<0,001)$; ils ont ensuite remonté, mais n'avaient pas atteint le niveau de départ après 9 à 18 mois $(75,1, p<0,001)$. Les scores d'état de santé (PORPUS-U) ont suivi la même tendance : 0,94 au départ; 0,81 après 3 mois $(p<0,001)$, et 0,88 après 9 à 18 mois $(p<0.001)$. Les facteurs de prédiction du score de QdVS qui diminuent sont le score PORPUS au départ, le recours à une technique chirurgicale préservant les filets nerveux et le tabagisme.

Conclusion : Il est reconnu que les scores des symptômes sont affectés jusqu'à 12 mois après la PR. Notre étude montre que l'état de santé global diminue également et demeure affecté un an après l'intervention chirurgicale.

\section{Introduction}

Many studies have explored the effects of radical prostatectomy (RP) on health-related quality of life (HRQoL). Most of these studies have focused on disease-specific qualityof-life domains, including sexual, urinary and bowel function. ${ }^{1,2}$ Although these aspects of quality of life are important, they are not the only areas affected. ${ }^{3}$ In addition, the relative importance of each of these domains is uncertain. Men may develop sexual dysfunction, for example, but may 
not regard this aspect of their life as being of major importance in the context of a cancer diagnosis. Few longitudinal studies have characterized the effect of treatment on overall (or global) HRQoL. ${ }^{2,4}$

One approach to measuring global HRQoL assesses how much a patient values his current health. This is expressed using the concept of utility. Utility is a global, preferencebased measure of HRQoL conventionally scaled from 0 (dead) to 1 (full health). Utilities take into account not only symptom severity but also a patient's personal attitudes and values toward the illness or symptoms. A patient's utility for his own health can be directly elicited from patients using methods such as the standard gamble. ${ }^{5}$ Utility may also be measured indirectly, using questionnaire-based instruments, such as the EQ-5D (all diseases/health outcomes) ${ }^{6}$ or the Patient-Oriented Prostate Utility Scale (PORPUS) (prostate cancer only). ${ }^{7-9}$

Utilities are particularly important in prostate cancer because many prostate cancer decisions, including optimal treatment for localized disease, have been shown to be "preference sensitive." ${ }^{10,11}$ The difference in overall health benefit (quality-adjusted survival) between treatments for localized prostate cancer is generally small. Thus, the right choice for an individual is determined not only by the strength of evidence around treatment efficacy, but also by how patients feel about potential outcomes of treatment.

Few studies have explored utility-based HRQoL outcomes after RP. ${ }^{8,12,13}$ Krahn and colleagues studied a group of patients with prostate cancer, and evaluated the impact of sexual, urinary and bowel dysfunction on health utilities. ${ }^{8}$ However, this was a cross-sectional study and the effects of treatment on health outcomes could not be directly measured. Other cross-sectional studies have also explored the effect of symptom severity on utility for current health status. ${ }^{13}$ This study expands upon previous work by prospectively studying the effect of RP on current health status, using validated instruments that measure health utility, erectile function and prostate symptoms.

Our primary objective was to examine the effects of RP on preference-based global HRQoL (utility) and to determine if there is a clinically significant change in utility from before surgery to 9 to 18 months after surgery. Secondary objectives include the assessment of changes in specific domains of HRQoL over time after RP.

\section{Methods}

\section{Study Sample}

Participants were recruited between July 2003 and June 2006 from the Prostate Centre at the University Health Network in Toronto, Ontario, Canada. New patients who were candidates for surgery were given a baseline self-administered questionnaire, which included questions about demographics and comorbid illnesses. Study instruments were administered at every follow-up visit and took approximately 10 minutes to complete. Responses were manually entered into the Prostate Cancer Database.

At the time of the study, 355 men had completed questionnaires prior to RP. Although a detailed log of all new patients undergoing RP was not kept, based on examining operating room lists and physician billings, less than $4 \%$ of RP patients did not complete the baseline questionnaire. Inclusion criteria for this study were: i) men treated with RP for clinically localized adenocarcinoma of the prostate, ii) completed baseline HRQoL measures within 9 months prior to RP, and iii) completed at least one follow-up questionnaire within 9 to 18 months after RP. Exclusion criteria were inability to read or understand English. The final study sample included 213 men. The main reason for exclusion was missing a follow-up questionnaire at 9 to 18 months post-RP.

Follow-up HRQoL assessments were dictated by usual clinical practice rather than fixed time points, and were grouped into the following 4 intervals to facilitate analyses: 0 to 3 months, 3 to 9 months, 9 to 18 months, and 18 to 30 months.

The Research Ethics Board at the University Health Network approved the project. Informed consent was obtained from each participant.

\section{Outcome Measures}

Baseline clinical information included height, weight, pretreatment prostate-specific antigen (PSA) level, clinical T stage and biopsy Gleason score. Comorbidity was evaluated using the Charlson Index ${ }^{14}$ based on patient self-report.

Our primary outcome measure was utility. Utility is used in decision analyses for groups of patients or individuals, ${ }^{15-17}$ in cost-effectiveness studies, ${ }^{18-20}$ as a measure of population health ${ }^{21}$ or as an outcome measure in clinical trials. ${ }^{22,23}$ It is a single number, conventionally scaled between " 1 " (full health) and " 0 " (dead) that represents that desirability of a health outcome, relative to these scale anchors.

We measured preference (i.e., utility) and non-preference-based HRQoL using the PORPUS. ${ }^{9}$ This 10 -domain multi-attribute health classification system measures a patient's physical and emotional status (Appendix). The PORPUS can be used as a disease-specific, non-preferencebased instrument, in which all items are weighted equally and normalized to provide a score between 0 and 100 (the PORPUS-P [psychometric]). The PORPUS can also be used with utility weights derived from prostate cancer patients to generate a utility score, scaled between 0 and 1 (the PORPUS- $U$ [utility]). Both the PORPUS-P and the PORPUS- 
Table 1. Baseline characteristics of study sample $(n=213$ )

\begin{tabular}{|c|c|}
\hline Age, y (mean \pm SD) & $60.8 \pm 7.1$ \\
\hline $\mathrm{BMI}, \mathrm{kg} / \mathrm{m}^{2}(\text { mean } \pm \mathrm{SD})^{*}$ & $26.7 \pm 3.2$ \\
\hline $\begin{array}{l}\text { Ethnicity, no. }(\%)^{\wedge} \\
\text { White } \\
\text { Other } \\
\text { Black }\end{array}$ & $\begin{array}{l}143(82.2) \\
21(12.1) \\
10(5.7)\end{array}$ \\
\hline $\begin{array}{l}\text { Charlson comorbidity score, no. }(\%)^{+} \\
0 \\
1 \\
\geq 2\end{array}$ & $\begin{array}{l}132(73.7) \\
35(19.6) \\
12(6.7)\end{array}$ \\
\hline $\begin{array}{l}\text { Smoking, no. (\%) } \\
\text { Past } \\
\text { Current } \\
\text { Never }\end{array}$ & $\begin{array}{c}42(19.7) \\
17(8.0) \\
59(27.7)\end{array}$ \\
\hline $\begin{array}{l}\text { Alcohol consumption, no }(\%)^{\dagger} \\
\text { Servings/wk, mean } \pm \mathrm{SD}\end{array}$ & $\begin{array}{l}97(78.2) \\
8.7 \pm 6.8\end{array}$ \\
\hline Use of erectile aid, no. (\%) & $6(2.8)$ \\
\hline PSA (ng/mL), ${ }^{* *}$ median (IQR) & $5.6(4.2-8.4)$ \\
\hline $\begin{array}{l}\text { Biopsy Gleason score } \\
\text { Mean } \\
\text { Median }\end{array}$ & $\begin{array}{c}7.0 \pm 0.9 \\
7.0\end{array}$ \\
\hline $\begin{array}{l}\text { Tumour stage, no. }(\%)^{\diamond} \\
\text { T1 } \\
\text { T2 }\end{array}$ & $\begin{array}{c}116(62.7) \\
69(37.3)\end{array}$ \\
\hline $\begin{array}{l}\text { Nerve sparing, no. (\%) } \\
\text { Yes - Bilateral } \\
\text { Yes - Unilateral } \\
\text { No } \\
\text { Unknown }\end{array}$ & $\begin{array}{c}127(59.6) \\
31(14.6) \\
50(23.5) \\
5(2.3)\end{array}$ \\
\hline $\begin{array}{l}\text { Year of surgery, no. (\%) } \\
2003 \\
2004 \\
2005 \\
2006\end{array}$ & $\begin{array}{c}14(6.6) \\
57(26.8) \\
104(48.8) \\
38(17.8)\end{array}$ \\
\hline $\begin{array}{l}\text { Margin status, no. (\%) } \\
\text { Negative } \\
\text { Focal positivity } \\
\text { Positive } \\
\text { Unknown }\end{array}$ & $\begin{array}{l}177(83.1) \\
18(8.5) \\
16(7.5) \\
2(0.9)\end{array}$ \\
\hline $\begin{array}{l}\text { Other treatment, no. (\%) } \\
\text { Prior to radical prostatectomy } \\
\text { Hormones } \\
\text { TURP } \\
\text { Adjuvant } \\
\text { Hormones } \\
\text { Radiotherapy } \\
\text { Radiotherapy + hormones }\end{array}$ & $\begin{array}{c}9(4.2) \\
7 \\
2 \\
19(8.9) \\
10 \\
4 \\
5\end{array}$ \\
\hline $\begin{array}{l}\text { Baseline HRQoL scores (mean } \pm \text { SD) } \\
\text { PORPUS - Psychometric }(n=213) \\
\text { PORPUS - Utility }(n=178) \\
\text { IIEF }(n=71) \\
\text { IPSS - Bothersome }(n=207) \\
\text { IPSS - AUA symptom }(n=198)\end{array}$ & $\begin{array}{l}83.9 \pm 11.1 \\
0.94 \pm 0.15 \\
20.7 \pm 5.6 \\
1.7 \pm 1.6 \\
8.1 \pm 7.0\end{array}$ \\
\hline \multicolumn{2}{|c|}{ 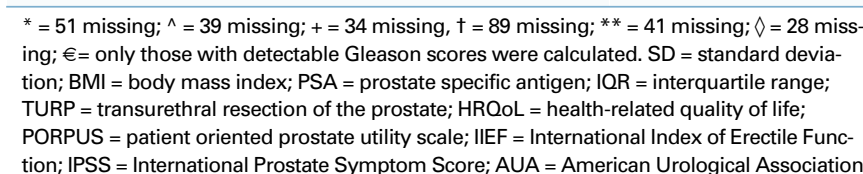 } \\
\hline
\end{tabular}

$U$ have been shown to have good reliability (PORPUS-P intraclass correlation coefficient [ICC] $=0.81$; PORPUS-U ICC $=0.72$ ), discriminant validity ${ }^{8,9}$ and responsiveness. ${ }^{24}$ Clinically important differences in PORPUS-P and PORPUS-U are 5 points and 0.05 units, respectively.

Urinary tract symptoms, function and control were evaluated using the International Prostate Symptom Score (IPSS). ${ }^{25}$ The IPSS has excellent reliability, validity and responsiveness (test-retest reliability of 0.92 and Cronbach's $\alpha$ of 0.86 ). ${ }^{25}$ Scores range from 0 to 41; higher scores indicate more severe symptoms.

The abridged International Index of Erectile Function (IIEF) was added partway through the study as an additional measure of erectile function. The IIEF measures male sexual function in 5 relevant domains. ${ }^{26}$ The total IIEF score can range from 5 to 25 , with higher scores representing better function.

\section{Statistical Analysis}

Baseline socio-demographic and clinical characteristics were described using means, proportions, and frequencies as appropriate. Mean PORPUS-P and PORPUS-U scores at each time point were calculated for all patients with valid responses. Simple imputation was performed using the mean response for other participants at that time point if one or two items were missing from a questionnaire. If more than two items were missing, the measurement for that clinic visit was excluded.

The primary analysis was a comparison of scores between baseline (pre-RP) and the 9- to 18-month time points using a paired t-test. Similar pairwise comparisons were conducted for other time points.

To understand the HRQoL effect of RP in men with normal function at baseline, we performed additional analyses on a subgroup restricted to those who reported normal sexual function (defined as PORPUS responses 1 or 2 to the question on sexual function (i.e., ability to have an erection sufficient for intercourse) at baseline. We calculated the percentage of men who reported this level of sexual function at subsequent time points. Similar analyses were done for men with normal urinary function, defined as a PORPUS bladder control question response of 1 or 2 (i.e., never or rarely leaks urine or loss of bladder control that did not interfere with daily activities). All 8 remaining domains were also examined using similar criteria.

Univariate and multivariable linear regression models were constructed to examine predictors of return to baseline HRQoL by 9 to 18 months. We considered the following variables: age; body mass index, comorbidity, ethnicity, tumour stage, Gleason score, nerve-sparing status, smoking status and year of surgery. Variables were retained in the multivariable model if the $p$-value was $<0.20$ in the univariate analysis. 
$\mathrm{Ku}$ et al.

A $p$-value of 0.05 was used to denote statistical significance. All statistical analyses were done using SPSS, version 15.0 (SPSS Inc., Chicago, Illinois).

\section{Results}

\section{Baseline characteristics}

A total of 213 men met the inclusion criteria. Baseline characteristics are shown in Table 1 . The mean age was 60.8 \pm 7.1 years. At baseline, the mean PSA level was $7.2 \pm$ $6.3 \mathrm{ng} / \mathrm{mL}$ and the median Gleason score was 7 .

Among the 213 RP procedures, 212 were open prostatectomies and 1 was laparoscopic. Most procedures were nerve-sparing $(\mathrm{n}=158,74.2 \%)$, of which $127(59.6 \%)$ were bilateral (Table 1).

The response rate for completed PORPUS questionnaires at each time point was: baseline $(100 \%) ; 0$ to 3 months $(82 \%) ; 3$ to 9 months ( $75 \%) ; 9$ to 18 months (100\%); and 18 to 30 months (79\%). The response rate for completed IPSS questionnaire at each time point was: baseline (93\%); 0 to 3 months (75\%); 3 to 9 months ( $71 \%) ; 9$ to 18 months

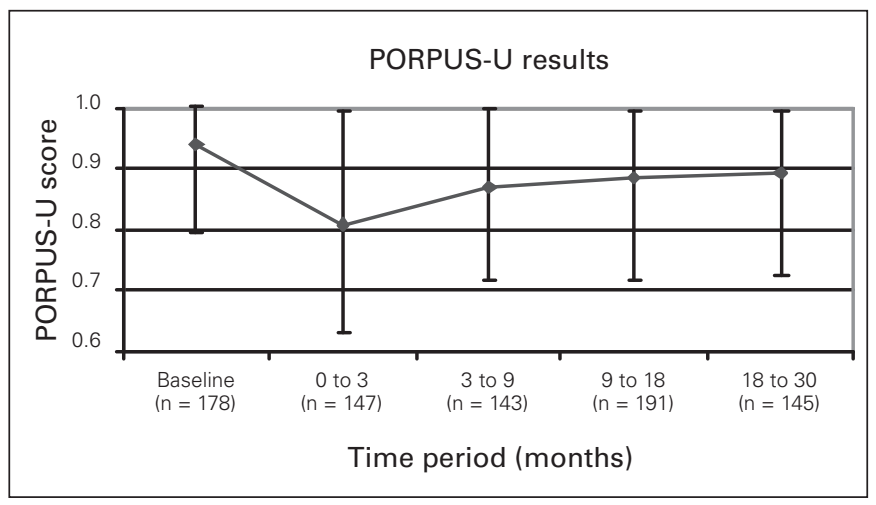

$\boldsymbol{A}$

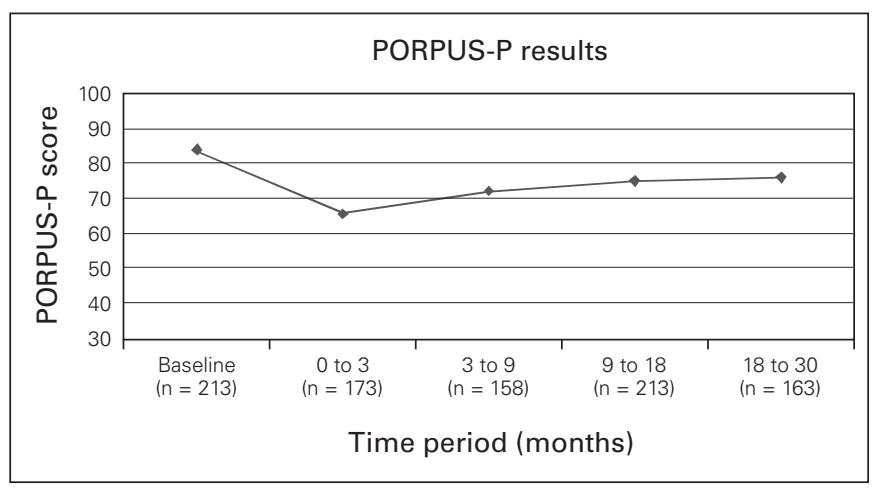

$\boldsymbol{B}$

Fig. 1. This graph shows the mean patient-oriented prostate utility scale (PORPUS) scores over time. Panel A shows PORPUS- Psychometric scores; panel B shows PORPUS-Utility scores.
(97\%); and 18 to 30 months (52\%). Lastly, the response rate for completed IIEF questionnaire at each time point was: baseline (33\%); 0 to 3 months $(24 \%) ; 3$ to 9 months (35\%); 9 to 18 months (56\%); and 18 to 30 months (35\%).

\section{PORPUS-U scores}

At baseline, the mean utility score for the cohort was high (mean PORPUS-U $=0.94,95 \%$ confidence interval $[\mathrm{CI}]$ 0.93-0.95) and higher than men of similar age in the general population $(0.80 \pm 0.20) .{ }^{21}$ Utility scores dropped sharply from baseline to 0 to 3 months (mean $0.81,95 \% \mathrm{Cl} 0.79$ $0.82, p<0.001)$, and improved modestly by 3 to 9 months (mean $0.87,95 \% \mathrm{Cl} 0.86-0.89, p<0.001$ ). By the 9 - to 18 -month range, utility scores had improved (mean 0.89 , $95 \% \mathrm{Cl} 0.87-0.90, p<0.001)$. Similar to global HRQoL, at 18 to 30 months, scores approached but did not return to baseline (mean 0.90, 95\% Cl 0.88-0.91, $p<0.001$ ) (Fig. 1a).

\section{PORPUS-P scores}

At baseline, patients' disease-specific HRQoL was high (mean PORPUS-P = 83.8, 95\% Cl 82.4-85.4). HRQoL scores demonstrated a sharp decline from baseline to 0 to 3 months (mean $65.6,95 \% \mathrm{Cl} 63.6-67.7, p<0.001$ ) but improved by 3 to 9 months (mean 72.2, 95\% Cl 70.3-74.2, $p<0.001$ ). Scores improved more slowly thereafter and HRQoL had not returned to baseline by 9 to 18 months (mean 75.1, 95\% Cl 73.6-76.8, $p<0.001$ ). At 18 to 30 months, scores were still improving, but the mean score of the cohort did not reach the baseline score (mean 76.2, 95\% Cl 73.7-78.4, $p<0.001$ ) (Fig. 1b).

\section{HRQoL domain changes over time}

Most men reported no sexual or bowel problems and no obstructive or irritative urinary problems at baseline (Fig. 2). Relative to other domains, sexual function and interest declined the most at 0 to 3 months and were affected through the 9 to 18 months of follow-up. Other domains that declined postoperatively included energy (mean item score 2.07, 95\% Cl 1.94-2.18, range 1-5) and urinary function (1.90, $95 \% \mathrm{Cl} 1.78-2.01$, range 1-5), both of which were slightly worse at 0 to 3 months ( 2.56 and 2.72 , respectively, $p<0.001$ ). Pain scores worsened immediately postoperatively (1.77, $95 \% \mathrm{Cl} 1.62-1.91)$, but were better than baseline by 3 to 9 months (1.46, 95\% Cl 1.34-1.58). By 9 to 18 months, pain scores returned to baseline $(1.31,95 \% \mathrm{Cl} 1.22-1.40$, $p>0.05)$, whereas both energy level $(2.23,95 \% \mathrm{Cl} 2.11$ $2.36, p<0.05)$ and urinary function $(2.01,95 \% \mathrm{Cl} 1.91$ $2.13, p<0.05)$ improved but did not return to baseline. The remaining PORPUS domains (emotional well-being, communication with doctor, family support and bowel function) did not significantly change at 0 to 3 months or 9 to 18 months ( $p>0.05$, for all of these domains). 


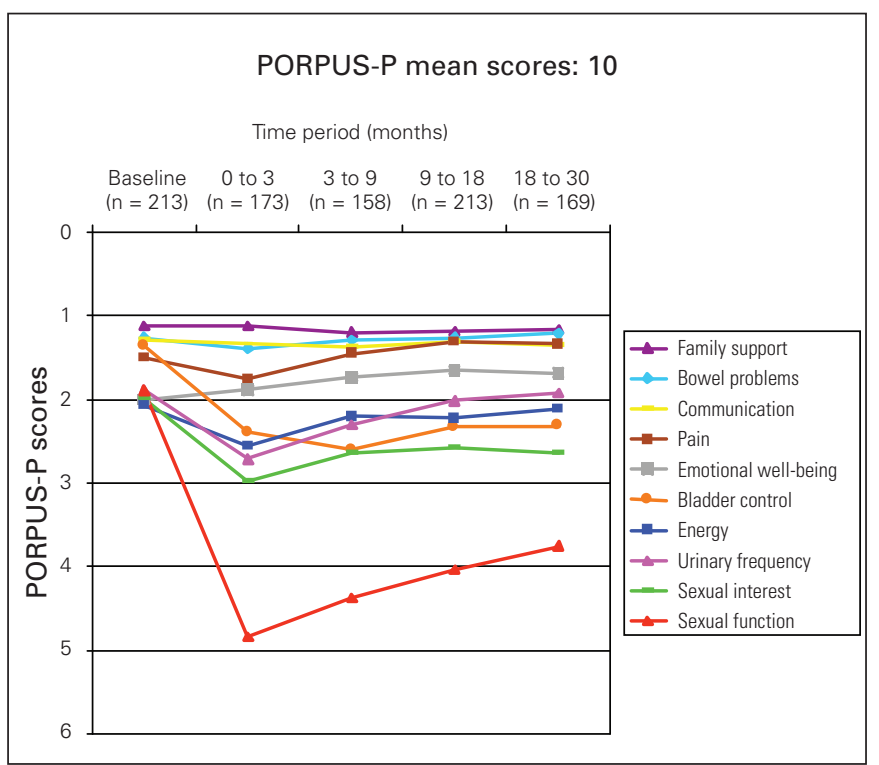

Fig. 2. The graph shows the trends in mean scores over time for each of the 10 patient-oriented prostate utility scale (PORPUS) domains from baseline to 18 to 30 months after surgery.

The IPSS scores worsened at 0 to 3 months $(11.46,95 \%$ Cl 10.33-12.54, $p<0.05)$, after which they improved to levels beyond baseline (baseline 8.03, 95\% Cl 7.07-9.03; 9 to 18 months $6.96,95 \% \mathrm{Cl} 6.21-7.77, p<0.05)$. The IIEF scores showed the same pattern as the PORPUS sexual domains, although data were only available for $71(33 \%)$ men (data not shown).

\section{Impact of RP on HRQoL among patients with normal function at baseline}

Among men with normal sexual function preoperatively, $2.1 \%$ (at 0 to 3 months), $7.4 \%$ (at 3 to 9 months), $18.1 \%$ (at 9 to 18 months) and $30.1 \%$ (at 18 to 30 months) were able to maintain full erections or erections sufficient for intercourse, but with some reduction in firmness (Table 2).

Among men with normal bladder control at baseline, recovery was more rapid. Whereas $27.0 \%$ of men had no instances or rare occasions of leaking urine or poor bladder control at 0 to 3 months, this figure rose to $73.0 \%$ at the 9- to 18-month range (Table 2). Results of other domains are shown in Table 2.

\section{Predictors of HRQDL recovery}

Univariate analyses using PORPUS-P revealed that having lower baseline PORPUS-P scores, being at the clinical T2 stage and being a non-smoker were associated with a smaller persistent decline in PORPUS-P scores at 9 to 18 months after RP $(p<0.05)$. Similar results were noted for the PORPUS-U score (data not shown).

The multivariable models for both PORPUS-P and PORPUS-U revealed that HRQoL score at baseline and current smoking were the most important predictors of change in HRQoL at 9 to 18 months after surgery $(p<0.05)$ (Table 3).

Table 2. Percentage of cohort with no impairment at baseline who reported no impairment at various follow-up time points, based on PORPUS domain

\begin{tabular}{|c|c|c|c|c|c|c|}
\hline PORPUS domain & $\mathrm{N}(\%)$ & Baseline & 0 to $3 \mathrm{mos}$ & 3 to $9 \mathrm{mos}$ & 9 to $18 \mathrm{mos}$ & 18 to $30 \mathrm{mos}$ \\
\hline Bladder control & 122 (57.3) & 100 & 27.0 & 61.5 & 73.0 & 76.0 \\
\hline Sexual drive & $84(39.4)$ & 100 & 59.5 & 60.7 & 66.7 & 72.3 \\
\hline Sexual function & $94(44.1)$ & 100 & 2.1 & 7.4 & 18.1 & 30.1 \\
\hline Urinary frequency & 88 (41.3) & 100 & 54.5 & 72.7 & 87.5 & 87.7 \\
\hline Bowel problems & $125(58.7)$ & 100 & 93.6 & 98.4 & 100 & 96.0 \\
\hline Emotional well-being & $106(49.8)$ & 100 & 89.6 & 92.5 & 91.5 & 89.8 \\
\hline Energy & $107(50.2)$ & 100 & 57.0 & 77.6 & 78.5 & 85.9 \\
\hline Pain & $120(56.3)$ & 100 & 81.7 & 90.8 & 95.0 & 90.5 \\
\hline Family support & $130(61.0)$ & 100 & 98.5 & 94.6 & 96.9 & 96.2 \\
\hline Communication with doctor & $118(55.4)$ & 100 & 92.4 & 95.8 & 96.6 & 98.9 \\
\hline
\end{tabular}

PORPUS $=$ patient-oriented prostate utility scale; $\operatorname{mos}=$ months 
$\mathrm{Ku}$ et al.

\begin{tabular}{|c|c|c|}
\hline Variable & $\begin{array}{l}\text { PORPUS-P } \\
\text { (p-value) }\end{array}$ & $\begin{array}{l}\text { PORPUS-U } \\
\text { (p-value) }\end{array}$ \\
\hline $\begin{array}{l}\text { Nerve-sparing } \\
\text { No } \\
\text { Yes } \\
\text { Unknown }\end{array}$ & $\begin{array}{c}\text { Referent } \\
0.123(0.087) \\
0.106(0.124)\end{array}$ & $\begin{array}{c}\text { Referent } \\
0.274(<0.001) \\
0.172(0.180)\end{array}$ \\
\hline Baseline PORPUS-P/U & $-0.466(<0.001)$ & $-0.552(<0.001)$ \\
\hline $\begin{array}{l}\text { Year of RP } \\
2003 \\
2004 \\
2005 \\
2006\end{array}$ & $\begin{array}{c}\text { Referent } \\
-0.087(0.453) \\
0.116(0.351) \\
-0.056(0.592)\end{array}$ & $\begin{array}{c}\text { Referent } \\
-0.187(0.119) \\
-0.049(0.702) \\
-0.005(0.964)\end{array}$ \\
\hline $\begin{array}{l}\text { T Stage } \\
\text { T1 } \\
\text { T2 }\end{array}$ & $\begin{array}{c}\text { Referent } \\
-0.090(0.163)\end{array}$ & $\begin{array}{c}\text { Referent } \\
-0.126(0.059)\end{array}$ \\
\hline $\begin{array}{l}\text { Smoking status } \\
\text { None } \\
\text { Previous } \\
\text { Current }\end{array}$ & $\begin{array}{c}\text { Referent } \\
-0.036(0.565) \\
-0.181(0.004)\end{array}$ & $\begin{array}{c}\text { Referent } \\
-0.049(0.430) \\
-0.192(0.003)\end{array}$ \\
\hline
\end{tabular}

PORPUS-P = patient-oriented prostate utility scale-psychometric; PORPUS-U = patientoriented prostate utility scale-utility; RP = radical prostatectomy.

\section{Sensitivity Analyses}

We examined the impact of using narrower time windows of \pm 3 months, \pm 2 months or \pm 1 month at 1 year rather than at 9 to 18 months. This showed virtually identical PORPUS-P and PORPUS-U scores using all four definitions (maximum mean differences of 0.79 [PORPUS-P] and 0.01 [PORPUS-U] units).

To exclude any impact of neoadjuvant or adjuvant therapy on our findings, we also reran our analyses after excluding patients who received neoadjuvant $(n=9)$ or adjuvant therapy $(n=19)$. Results were unchanged (data not shown).

\section{Discussion}

Our study found that disease-specific HRQoL scores (PORPUS-P) declined significantly after surgery and improved, but did not return to baseline (pre-surgery) levels by 9 to 18 months. Following this cohort to the 18- to 30month interval, the same pattern was observed: scores did not return to baseline. We observed a similar trend when quality of life was measured using a global, preferencebased measure (utility). Sexual function and interest were the two prostate-specific domains that declined most after surgery and remained most affected a year later.

Perhaps the signal contribution of this study is its evaluation of global health status post-RP. Our study showed that utility scores were, on average, 0.06 points (on a 0 to 1 scale) lower than baseline scores at 9 to 18 months post-
RP. Expressing these differences using conventional utility scaling methods, post-RP patients would be willing to trade away $6 \%$ of their remaining life expectancy to return to their pre-surgery health status (time-tradeoff method). Alternately, patients would, on average, be indifferent to either remaining at their post-RP health status or taking a $6 \%$ chance of death to return to pre-RP health (standard gamble method). This difference is small to moderate in size, but clinically important in the global health status among patients who underwent RP.

These findings are, to our knowledge, new. Utilities have been described in several cross-sectional studies of mixed prostate cancer patients. ${ }^{8,13,24}$ These studies suggested that sexual, urinary and bowel dysfunction affect utility, but were not able to definitively link treatment to health impairments. We are unaware of other utility studies highlighting the long-term effects of RP.

Numerous studies have prospectively examined HRQoL in men after RP. Perhaps the best-known is the Prostate Cancer Outcomes Study (PCOS). ${ }^{27}$ The PCOS found that treatment with RP led to significant sexual dysfunction and some decline in urinary function. At 24 months, $8.7 \%$ of men were bothered by lack of urinary control and $41.9 \%$ reported that sexual function was a moderate-to-big problem in their daily lives. ${ }^{28}$

Sanda and colleagues ${ }^{29}$ recently reported that urinary incontinence was at its worst by 2 months after surgery, after which it improved in most patients. A total of $26 \%$ of the patients reported that sexual function was a "big problem," while $76 \%$ reported urinary incontinence was a "very small" problem or "no problem at all" 1 year after RP. Numerous other studies have demonstrated that the two main long-term side effects after RP are sexual dysfunction $^{1,2,28,30,31}$ and urinary incontinence, ${ }^{28,32}$ with recovery occurring over 2 to 3 years. 2,28,32

Other HRQoL domains that were affected after surgery in our study included pain and energy. Several studies have shown that pain and energy worsen immediately post-RP but usually improve by 12 months..$^{2,30,32}$

The follow-up assessment periods demonstrated a decrease in the number of patients over time. However, each follow-up period had a $75 \%$ minimum response rate for our primary outcome measure. The remaining proportion of incomplete questionnaires or lost to follow-up can be explained by noncompliant patients and/or staff members, particularly in a fast-paced urology clinic. Our follow-up periods were relatively wide to maximize our sample size. The questionnaires were not distributed randomly. Our protocol included that clinic lists were thoroughly reviewed by research coordinators, prior to clinic appointments, to ensure patients were targeted. In addition, the IIEF survey was introduced partway into our study, thereby explaining its low response rates during the early 
time periods. Lastly, certain patients did not reach the time period in question (i.e., 18 to 30 months) when data were first being analyzed for manuscript purposes (i.e., in late 2005 or 2006 RP patients had not reached the follow-up at 18 to 30 months post-RP period yet).

Our study has several strengths. It was a prospective longitudinal study, and included detailed baseline and follow-up information at clinically relevant time points in a relatively large group of men. We used validated and robust measures, such as the PORPUS, IPSS and IIEF. The latter two instruments corroborated our findings from the PORPUS. We also recognize several limitations. First, our sample was recruited from one academic centre with highly experienced uro-oncologic surgeons. Thus, while our results are comparable to those reported in case series from other academic centres, results may not be generalizable to all practice settings. Second, patient follow-up was dictated by usual clinical practice rather than fixed time points. Although our follow-up periods were relatively wide, to accommodate clinically dictated follow-up and to maximize our sample size, using narrower time windows showed virtually identical results. Third, some patients were lost to follow-up prior to the 9- to 18-month visit; however, such patients had similar baseline scores to included patients (data not shown).

\section{Conclusion}

In summary, disease-specific HRQoL (PORPUS-P scores) declined significantly after RP and did not return to baseline by 2 years. Overall utility followed a very similar pattern to overall HRQoL. While individual responses to surgery will vary, these results show that, for a group of prostate cancer patients, surgery had clear effects not only on symptoms but on overall health status at the 1- and 2-year time points. This information should be incorporated into informed consent discussions prior to surgery. Additionally, decision modelers and health economists attempting to compare treatment options for localized prostate cancer should use data, such as those reported in this study, that directly evaluate the impact of surgery on overall health.

From the University of Waterloo, University Health Network, University of Toronto, Toronto Health Economics and Technology Assessment Collaborative (THETA)

Competing interests: None declared.

This paper has been peer-reviewed.

Acknowledgements: Supported in part through the F. Norman Hughes Chair in Pharmacoeconomics, Faculty of Pharmacy (MK), the Fleck Tanenbaum Chair in Prostatic Diseases (JT), and by a Research Scientist Award from the Canadian Cancer Society (SMHA).

\section{References}

1. Litwin MS, Gore IL, Kwan L, et al. Quality of life after surgery, external beam irradiation, or brachytherapy for early-stage prostate cancer. Cancer 2007;109:2239-47.

2. Litwin MS, Melmed GY, Nakazon T. Life after radical prostatectomy: a longitudinal study. J Urol 2001;166:587-92.

3. Wei JT, Dunn RL, Sandler HM, et al. Comprehensive comparison of health-related quality of life after contemporary therapies for localized prostate cancer. J Clin Oncol 2002;20:557-66.

4. Kawanishi Y, Lee KS, Kimura K, et al. Effect of radical retropubic prostatectomy on erectile function, evaluated before and after surgery using colour Doppler ultrasonography and nocturnal penile tumescence monitoring. BJU Int 2001;88:244-7.

5. Froberg DG, Kane RL. Methodology for measuring health-state preferences—II: Scaling methods. J Clin Epidemiol 1989;42:459-71.

6. Johnson JA, Pickard AS. Comparison of the EQ-5D and SF-12 health surveys in a general population survey in Alberta, Canada. Med Care 2000;38:115-21.

7. Krahn MD, Ritvo P, Naglie G, et al. Construction of PORPUS (Patient Orented Prostate Utility Scale): an Empirically Derived Multiattribute Health State Classification System for Prostate Cancer. J Clin Epidemiol 2000;53:920-30

8. Krahn M, Ritvo P, Irvine J, et al. Patient and community preferences for outcomes in prostate cancer: implications for clinical policy. Med Care 2003;41:153-64.

9. Ritvo P, Irvine J, Naglie G, Tomlinson G, Bezjak A, Matthew A, et al. Reliability and validity of the PORPUS, a combined psychometric and utility-based quality-of-life instrument for prostate cancer. I Clin Epidemiol 2005;58:466-74.

10. Alibhai SMH, Naglie G, Nam R, et al. Do older men benefit from curative therapy of localized prostate cancer? J Clin Oncol 2003;21:3318-27.

11. Krahn MD, Mahoney JE, Eckman MH, et al. Screening for prostate cancer - a decision analytic view. JAMA 1994;272:773-80.

12. Albertsen PC, Nease RF, Potosky AL. Assessment of patient preferences among men with prostate cancer. J Urol 1998;159:158-63

13. Bremner KE, Chong CA, Tomlinson $\mathrm{G}$, et al. A review and meta-analysis of prostate cancer utilities. Med Decis Making 2007;27:288-98.

14. Charlson ME, Pompei P, Ales KL, Mackenzie CR. A new method of classifying prognostic comorbidity in longitudinal studies: development and validation. J Chronic Dis 1987;40:373-83.

15. Kattan MW, Cowen ME, Miles BJ. A decision analysis for treatment of clinically localized prostate cancer. J Gen Intern Med 1997;12:299-305.

16. Svatek RS, Lee JJ, Roehrborn CG, et al. The cost of prostate cancer chemoprevention: a decision analysis model. Cancer Epidemiol Biomarkers Prev 2006;15:1485-9.

17. Konski $A$, Watkins-Bruner D, Feigenberg $S$, et al. Using decision analysis to determine the cost-effectiveness of intensity-modulated radiation therapy in the treatment of intermediate risk prostate cancer. Int $J$ Radiat Oncol Biol Phys 2006;66:408-15.

18. Svatek RS, Lee JJ, Roehrborn CG, et al. Cost-effectiveness of prostate cancer chemoprevention: a quality of life-years analysis. Cancer 2008; 112:1058-65.

19. Coley CM, Barry MJ, Fleming C, et al. Early detection of prostate cancer. Part II: estimating the risks, benefits, and costs. Ann Intern Med 1997;126:468-479.

20. Hillner BE, McLeod DG, Crawford ED, Bennett CL. Estimating the cost effectiveness of total androgen blockade with flutamide in M1 prostate cancer. Urology 1995;45:633-40.

21. Mittmann N, Trakas K, Risebrough N, Liu BA. Utility scores for chronic conditions in a community-dwelling population. Pharmacoeconomics 1999:15:369-76.

22. Rosendahl I, Kiebert GM, Curran D, et al. Quality-adjusted survival (Q-TWIST) analysis of EORTC trial 30853: comparing goserelin acetate and flutamide with bilateral orchiectomy in patients with metastatic prostate cancer. Prostate 1999;38:100-9.

23. Schroder FH. Screening for prostate cancer (PC)-an update on recent findings of the European Randomized Study of Screening for Prostate Cancer (ERSPC). Urol Oncol 2008;26:533-41.

24. Krahn $M$, Bremner $K E$, Tomlinson $G$, et al. Responsiveness of disease-specific and generic utility instruments in prostate cancer patients. Qual life Res 2007;16:509-22.

25. Barry MJ, Fowler FJ, Jr., O'Leary MP, et al. The American Urological Association symptom index for benign prostatic hyperplasia. The Measurement Committee of the American Urological Association. J Urol 1992;148:1549-57; discussion 1564.

26. Rosen RC, Cappelleri JC, Smith MD, et al. Development and evaluation of an abridged, 5-item version of the International Index of Erectile Function (IIEF-5) as a diagnostic tool for erectile dysfunction. Int J Impot Res 1999;11:319-26.

27. Potosky AL, Harlan LC, Stanford JL, et al. Prostate cancer practice patterns and quality of life: the Prostate Cancer Outcomes Study. J Natl Cancer Inst 1999;91:1719-24. 
$\mathrm{Ku}$ et al.

28. Stanford JL, Feng Z, Hamilton AS, et al. Urinary and sexual function after radical prostatectomy for clinically localized prostate cancer: the Prostate Cancer Outcomes Study. JAMA 2000;283:354-60.

29. Sanda MG, Dunn RL, Michalski J, et al. Quality of life and satisfaction with outcome among prostatecancer survivors. N Engl J Med 2008;358:1250-61.

30. Lubeck DP, Litwin MS, Henning JM, et al. Changes in health-related quality of life in the first year after treatment for prostate cancer: results from CaPSURE. Urology 1999;53:180-6.

31. Litwin MS, Flanders SC, Pasta DJ, et al. Sexual function and bother after radical prostatectomy or radiation for prostate cancer: multivariate quality-of-life analysis from CaPSURE. Cancer of the Prostate Strategic Urologic Research Endeavor. Urology 1999;54:503-8.

\section{Appendix. The Prostate-Oriented Record of Psychometric and} Utility-Based Outcomes Scale

\section{Pain and disturbing body sensations}

1. No pain and disturbing body sensations.

2. Mild pain or disturbing body sensation that does not limit any activities (e.g., work, social, sexual, sleep).

3. Moderate pain or disturbing body sensations that limits a few activities.

4. Moderate to severe pain or disturbing body sensations that limits many activities.

II. Energy

1. Very full of energy, lots of pep.

2. Fairly energetic, no limitation of activities (e.g., work, social, sexual).

3. Moderate reduction in energy or pep that limits some activities.

4. Generally low energy or pep that limits some activities.

5. No energy or pep at all. I feel drained, and many activities are limited.

III. Support from family and friends

1. Most of the time feel supported by my spouse, family, and friends.

2. A fair amount of the time feel supported by my spouse, family, and friends.

3. Occasionally feel supported by my spouse, family, and friends.

4. Rarely feel supported by my spouse, family, and friends.

IV. Communication with doctor (primary caregiver for prostate cancer, may be specialist or family doctor)

1. Always able to express my concerns to my doctor and get all the information or advice I need.

2. Most of the time, able to express my concerns to my doctor and get all the information or advice I need.

3. Some of the time, able to express my concerns to my doctor and get all the information or advice I need.

4. Rarely able to express my concerns to my doctor and get all the information or advice I need.

V. Emotional well-being

1. Generally happy and free from worry, sadness, or frustration.

2. A little worry, sadness, or frustration.

3. Moderate worry, sadness, or frustration.

4. Quite a bit of worry, sadness, or frustration.

5. Extreme worry, sadness, or frustration.
32. Smith DS, Carvalhal GF, Schneider K, et al. Quality-of-life outcomes for men with prostate carcinoma detected by screening. Cancer 2000;88:1454-63.

Correspondence: Jennifer Ku, 620 University Avenue, Toronto, ON M5G 2Cl; fax: 416-5989997; jku@ahsmail.uwaterloo.ca

VI. Urinary frequency (need to pass urine frequently during the day or night) and urgency (difficulty delaying urination after the urge is felt to urinate and ability to "hold it")

1. No urinary frequency or urgency.

2. A little urinary frequency or urgency, does not interfere with sleep or other activities (e.g., work, social),

3. Some urinary frequency or urgency that interferes with sleep or other activities, may need to plan ahead.

4. Quite a bit of urinary frequency or urgency, need to be near a bathroom most of the time.

5. Extreme urinary frequency or urgency, need to be near a bathroom always.

VII. Leaking urine/poor bladder control

1. Never, under any circumstances leak urine or lose bladder control.

2. On rare occasions, leak urine or lose bladder control, does not interfere with any activities (e.g., work, social, sexual, sleep).

3. Occasionally leak urine or lose bladder control, interferes with a few activities.

4. A moderate amount of the time, leak urine or lose bladder control, interferes with some activities.

5. Most of the time, leak urine or have poor bladder control, interferes with many activities.

6. Require a clamp, catheter, or collecting bag, because leaking urine or poor bladder control

VIII. Sexual function (problems with achieving/maintaining an erection)

1. Full erections sufficient for intercourse.

2. Erections sufficient for intercourse, but some reduction in firmness.

3. Erections sufficient for masturbation or foreplay only.

4. Erections, but not firm enough for any sexual activity.

5. No erections at all.

\section{Sexual interest/drive}

1. Normal amount of sexual drive and interest for you.

2. A little decrease of sexual drive or interest for you.

3. Moderate decrease of sexual drive or interest for you.

4. Substantial decrease of sexual drive or interest for you.

5. No sexual drive or interest.

X. Bowel problems: diarrhea, rectal discomfort (pain, burning or irritation), or constipation

1. No diarrhea, rectal discomfort, or constipation.

2. Occasionally have diarrhea, rectal discomfort, or constipation.

3. Frequently have diarrhea, rectal discomfort, or constipation.

4. Nearly always have diarrhea, rectal discomfort, or constipation. 